\title{
Exploring College Students' Biopsychosocial Spiritual Wellbeing and Problems during COVID-19 through a Contextual and Comprehensive Framework
}

\author{
Habil Otanga ${ }^{1}$ (D) Ahmet Tanhan ${ }^{2,3,4,5,6}$ (D) Phelista Marura Musılı ${ }^{7}$. \\ Gökmen Arslan $^{8,9}$ (D) Metin Buluş ${ }^{6}$ (D)
}

Accepted: 18 October 2021 /Published online: 1 November 2021

(c) The Author(s), under exclusive licence to Springer Science+Business Media, LLC, part of Springer Nature 2021

\begin{abstract}
College students in Kenya have experienced many mental health issues, and there is little well-grounded research on this topic. Therefore, in this current study, we aimed to explore college students' biopsychosocial spiritual wellbeing and problems from an Ecological Systems Theory (EST) perspective. Due to lack of previous well-grounded mental health research and services, we collaborated with the college students from the beginning of the study and acted with them to shape the research. Based on all these, we called our theoretical framework for this current paper as exploring college students' biopsychosocial spiritual wellbeing and problems from the EST perspective. We examined college students' $(N=518)$ mental health experiences during the COVID-19 pandemic through six items to measure psychosomatic problems (sadness, anxiety, frustration, stress, loneliness, and withdrawal) and their coping mechanisms (talking to family/friends, physical exercise, social media, reading books, hobbies, spiritual activities, alcohol/drugs, COVID-19 information). Gender and age explained a trivial amount of variance, about $1 \%$, in psychosomatic problems in model one. With the inclusion of the coping strategies and demographic factors (age and gender), the second model explained $24 \%$ of the variance in psychosomatic problems. In the second model, the highest effect size originated from talking to family/friends and use of social media. In addition, change in sleeping patterns, sadness, anxiety, and frustration were reported with one in three reporting "poor" or "fair" mental health. In light of the larger COVID-19 and college students' mental health literature, we discussed the present findings and provided recommendations.
\end{abstract}

Keywords Coping strategies · COVID-19 $\cdot$ Mental health $\cdot$ College students · Psychopathology $\cdot$ Positive psychology $\cdot$ Social support

COVID-19 pandemic has caused biopsychosocial spiritual and economic issues for many countries while affecting some countries and populations disproportionately (Ceri \& Cicek, 2020; Tanhan, 2020; Tanhan et al., 2020). As a result, many governments took

Habil Otanga

habil@uonbi.ac.ke

Extended author information available on the last page of the article 
unprecedented measures to curb the spread of the disease. Social distancing measures as well as lockdowns have been implemented across the globe (Doyumğaç et al., 2021; Tanhan et al., 2021a; Tümkaya et al., 2021). Previous researchers found that people in different countries face many biopsychosocial, spiritual, and economic issues during this difficult time affecting people at individual, group, and community levels (Shigemura et al., 2020; Subasi et al., 2021; Tanhan, 2020; Tanhan et al., 2021b, 2021c; Yıldırım et al., 2020) as well as family level (Genç et al., 2021; Tanhan, 2020; Tanhan et al., 2021a). Therefore, researchers stressed the importance of conducting research based on a well-grounded, comprehensive, and contextually sensitive theoretical framework to improve evidencebased interventions (Subasi et al., 2021; Tanhan, 2020; Tanhan et al., 2021a) rather than just using already established surveys for some other countries and/or contexts (Tanhan, 2020) although they might have some advantages. Based on all these, it was crucial to approach the pandemic in Kenya from such a contextual perspective to shape the current research from the beginning. To the best of our knowledge, this is the first study focused on COVID-19-associated mental health among university students in Kenya.

\section{Theoretical Framework}

Some researchers recommended focusing on positive psychological orientations and psychopathology, rather than just focusing on one of them, to come with more effective results and implications (Tanhan, 2020; Tanhan et al. 2020). They also stressed how most of the researchers across the globe focused on psychopathology in general and during COVID19. Therefore, in this current study, we paid attention to have a theoretical framework that stresses these two aspects and is contextually sensitive. Tanhan and colleagues (Tanhan et al. 2020) proposed a new conceptual framework using Acceptance and Commitment Therapy (ACT) within Ecological Systems Theory Perspective (EST) to understand one's psychopathology and wellbeing. Based on this framework, we called our theoretical framework for this current paper as exploring college students' biopsychosocial spiritual wellbeing and problems from the EST perspective. In this way, the framework is sensitive to the context of Kenya and is comprehensive to allow us to examine both wellbeing and psychopathology.

In the mental health profession, it is very common to see providers and researchers acting from a medical perspective meaning only focusing on abnormality and individual level (Tanhan, 2019; Tanhan \& Strack, 2020; Tanhan \& Young, 2021a). However, such a medical and reductionist perspective may not be as effective as more comprehensive and contextual approach that also includes medical approach (Tanhan, 2020; Tanhan \& Francisco, 2019). Bronfenbrenner (1977) offered a comprehensive framework of multiple factors that have impact on individuals and communities throughout their lives. Bronfenbrenner described the four main systems that include microsystem, mesosystem, exosystem, and macrosystem which interact to create an individual's dynamic daily contexts. According to the model, the individual is at the center and other systems are nested around them, constantly affecting the individuals as the individual impacts these systems (Tanhan, 2019; Tanhan \& Young, 2021b). Given the size and scope of the various ecological systems at play, systems are much more impactful on the individual than the inverse (Tanhan \& Francisco, 2019). Many researchers from various disciplines have utilized EST in conducting research, developing and implementing effective services (Arslan \& Tanhan, 2019, 2019; Arslan et al., 2020; Çiçek et al., 2020, 2021; Doyumğaç et al., 2021; Tanhan, 2020; Tanhan 
\& Strack, 2020; Tanhan \& Young, 2021a, 2021b). All these research series indicate that a contextual approach to understand and address mental health issues and wellbeing is necessary compared to choosing and using an already established questionnaire from an acontextual perspective. Tanhan $(2019,2020)$ highlighted the need of having partners from each level of EST to shape a comprehensive, well-grounded, and easily flowing research process. The researcher especially stressed how having different allies at different levels of EST can affect advocacy at a larger level, with less energy, and with much more effect.

\section{Mental Health Experiences during COVID-19}

Majority of the available literature on the psychological effect of COVID-19 is from China. Whereas the lengthy isolation, containment, and many unexpected changes are likely to have significant mental health implications on students, little is documented so far. Most of the studies on mental health have focused on health workers, adolescents, and the general population without specific focus on college students. These studies show increases in stress, anxiety, and depressive thoughts (Alsaqri et al., 2020; Cao et al., 2020; Hintz et al., 2015; Islam et al., 2020; Son et al., 2020; Sundarasen et al., 2020). Many students tend to experience a sense of loneliness and isolation (Zhai \& Du, 2020) particularly when there are restrictions in their movements and social interactions.

Although different types of vaccines have been developed and many countries have started administering them; COVID-19 still appears to be threatening to many students and even professional health workers (Kwok et al., 2021; Tanhan et al., 2021a, 2021b, 2021c). Therefore, the virus keeps inducing worries regarding the vaccines and their future effectiveness with some new variants of the virus being identified across the globe (Tanhan et al., 2021a, 2021b, 2021c). This may be exacerbated by the current grim economic challenges which may further disrupt their studies, thus compounding their fears. Moreover, there may be concerns about completion of their education within scheduled time frames which may delay their entry into the job market. These uncertainties coupled with the fear of getting infected could result in anxiety disorders (Goyal et al., 2020). Galea et al. (2020) predict an increase in anxiety, depression, loneliness, substance abuse as well as domestic violence. The situation may have a more profound impact for students with underlying mental health conditions.

An existing body of literature shows that reduced social interactions predict numerous mental and emotional disturbances including major depression and schizophrenia (Fiorillo \& Gorwood, 2020); stress, irritability, panic attacks, anger, insomnia, and post-traumatic stress symptoms (Brooks et al., 2020; Pfefferbaum \& North, 2020); and somatic experiences including change in eating and sleeping patterns (Son et al., 2020). In another related study, Sundarasen et al. (2020) reported that students who stayed alone experienced higher anxiety compared to those who stayed with family and friends. It is expected that the sudden threat to their safety and security during COVID-19 increased feelings of loneliness.

A number of demographic factors including gender are increasingly cited as important determinants of mental health during COVID-19. For instance, Liang et al. (2020) reported significantly higher disturbances to health in men than women and the differences were attributed to different coping styles and social roles. Similarly, Islam et al. (2020) found that males had higher depressive symptoms and anxiety than females. Contrastingly, Sundasaren and others (Sundarasen et al. 2020) found increased odds of anxiety among female students compared to male students. This finding is explained in terms of females 
expressing more emotions than men, lower uncertainty threshold, and lesser coping strategies in times of uncertainty and stressful situations. Furthermore, divorced or widowed individuals had significantly higher PTSD and disturbances on health which was likely due to lack of support against negative emotions and depressive symptoms and lack of communication. This finding on the role of family contradicts Islam et al. (2020) who found that students living with families were 2.6 times more likely to show symptoms of anxiety. With regard to age differences, some studies report that perceived stress decreases with age and older adults employ more effective coping resources compared to younger adults due to experience and resilience built over the years (Calborean et al., 2017; Monteiro et al., 2014; Zimmer-Gembeck \& Skinner, 2011). However, we did not come across any studies in terms of age difference and its relationship with decreased stress in the context of COVID-19.

\section{Coping Strategies during the Pandemic}

Selye's (1950) systemic theory views stress in terms of a pattern of non-specific responses or changes of the body induced by any demands made upon it. When faced with stress, individuals use up body resources and when depleted, they exhibit symptoms. Common symptoms experienced may include lethargy, changes in appetite or sleep patterns, loss of interest as well as susceptibility to illnesses due to a weakened immune system. This implies that critical life events including COVID-19 are likely to test individuals' mental resources and ultimately trigger coping strategies.

A body of literature indicates that a large percentage of students rely on negative coping strategies (Tanhan, 2020). For instance, Son et al. (2020) found that majority of students used strategies such as ignoring the news about COVID-19, sleeping longer, distracting themselves by doing other tasks, and drinking or smoking. Approximately one third used positive coping methods such as meditation and breathing exercises, spiritual measures, keeping routines, and positive reframing. Among those who used self-management strategies, hobbies, physical exercise, social media, listening to music, and reading were frequently used. In addition, communicating with their families and friends virtually was used to deal with stress and anxiety during COVID-19. In addition, Islam et al. (2020) found lower anxiety among students who reported having physical exercise. Similar findings by Khan et al. (2020) show significant negative correlations between physical exercise and scores on the DASS depression subscale. Furthermore, recreational activities including watching TV, reading story books, and playing online games reduced stress while inadequate valid information on COVID-19 was associated with higher stress.

A theoretical model by Lazarus and Folkman (1984) distinguish between problemand emotion-focused copings. Problem-focused approaches direct all efforts at changing the stressful situation, and therefore assume individuals' agency in seeking solutions and plans of action (Shin et al., 2014; Tanhan, 2019). For instance, the individual is likely to focus on removing, avoiding, or diminishing the threat (Mayordomo-Rodríguez et al., 2015; Tanhan, 2019) which may result in reducing the distress. This can also be achieved by seeking information about the stressor. Such strategies work well in situations where the threat can be altered. Emotion-focused coping aims to reduce the emotional reactions that may result from the stress caused by a stressor perceived to be beyond the individual's control. Some of these strategies may include denial, 
acceptance, seeking emotional support, and religion (Holmes et al., 2020; Lazarus \& Folkman, 1984; Tanhan, 2020); and meditation, distractions, comfort eating, drinking, and using drugs (McLeod, 2015) among others.

Many authorities argue that problem-focused strategies tend to be more effective than emotion-focused ones because they target the source of the stressor and thus deal with the problem. However, numerous studies have found that some forms of emotionfocused coping such as seeking emotional support, reappraisal, and spiritual beliefs may actually have positive outcomes (Shin et al., 2014; Tanhan, 2020). In addition, although problem-focused strategies may seem to be effective with long-term solutions (McLeod, 2015), they may not be applicable in some situations such as loss and grief since this is beyond one's control (Tanhan, 2019). The COVID-19 pandemic and its consequences (e.g., depression, anxiety, isolation) present students with a complex situation which demands for a variety of coping mechanisms (Tanhan et al., 2021a, 2021b, 2021c).

Gender disparities have been noted in coping styles. More females use emotionfocused coping as opposed to their male counterparts who focus more on problemfocused coping strategies (Makhbul \& Hasun, 2011; Monteiro et al., 2014; Tanhan, 2020). In some cases, males tend to use alcohol and other substances as a coping strategy (Panayiotou et al., 2017). These gender disparities could be attributed to social, cultural, and developmental aspects whereby females and males are socialized to adopt socially acceptable gender-specific behaviors (Tanhan, 2020). In fact, a growing body of literature focuses on the role of culture in stress and coping mechanisms (Tanhan, 2020; Tanhan et al., 2020). While stress and coping are universal experiences, cultural diversities are crucial in determining how a person responds to stressful events (Kuo, 2011). According to Lazarus and Folkman (1984), the whole process of appraising life events and the individuals' ways of coping are largely influenced by cultural beliefs and norms. Similarly, Tanhan, 2020 and Tanhan and others (Tanhan et al., 2020) also stressed culturally sensitive approaches to provide interventions that (a) address biopsychosocial spiritual problems and (b) enhance biopsychosocial spiritual wellbeing rather than just stressing psychopathology. Research also indicates that age differences influence the types of coping strategies used. Older persons tend to use more effective coping approaches (Monteiro et al., 2014). This implies that strategies considered more effective such as problem focused may be employed more frequently by the older student population.

The Ministry of Health (Ministry of Health 2020) in Kenya has formulated comprehensive guidelines which emphasize the need for individuals to recognize the emotional distress, worry, or anxiety they are experiencing. In addition, the guidelines stress on educating the public on signs and symptoms of the mental conditions as well as the "helpful" and "unhelpful" ways of coping. However, as individuals continue experiencing the pandemic, they are likely to adopt different response patterns that are dependent on individual vulnerability and resources available for coping. The preceding theoretical framework (Lazarus \& Folkman, 1984; Selye, 1950) shows that in periods of stress, including reduced social interactions, individuals are likely to develop psychosomatic problems and use coping mechanisms that either seek to change the stressful situations or reduce the emotional reactions due to the stressor(s).

Against the background of the literature reviewed, we had two main goals: (a) to examine the association between students' psychological health problems and coping strategies, and (b) explore gender and age differences in student experiences of psychological health and coping strategies while under isolation due to government-sanctioned containment measures against COVID-19. 


\section{Method}

\section{Participants}

Power analysis results suggested that 171 participants are needed to detect a medium effect with a power rate of $80 \%\left(R^{2}=.09\right.$ per Cohen's (1988) guideline, which corresponds to $\left.f^{2}=.10\right)$. The preliminary required sample size was determined using pwr.f2.test $(\mathrm{u}=10, \mathrm{v}=\mathrm{NULL}, \mathrm{f} 2=0.10$, sig. level $=0.05$, power $=0.80)$ function in the pwr $\mathrm{R}$ package (Champely, 2020). $\mathrm{u}=10$ is the numerator degrees of freedom and $\mathrm{v}=$ NULL is the denominator degrees of freedom and is to be estimated. Results suggested that $\mathrm{v}=161$, which means along with the degrees of freedom consumed by the predictors (two demographic and eight coping strategies), 171 subjects are needed. However, we collected data from as many participants as possible $(N=518)$, which is well beyond 171 . This reduces chances of inconclusive results.

The sample was restricted to 518 internet-using university students ( $64.5 \%$ female) whose age ranged from 18 to 55 (median group $=18-25$ years). The students were identified by posting a message to a number of university discussion groups indicating the nature of the questionnaire and its link. Snowball sampling was used where participants were requested to share the link with friends using their institutional discussion groups. The study was restricted to university students because only university email addresses could be used to access the link.

\section{Measures}

Based on our theoretical framework, we collaborated with our partners including some students and academicians to come with the most reported issues and strengths to construct a final version of the questionnaire. We also benefited from well-known scales to measure psychopathology (e.g., Beck Depression Inventory, Beck Anxiety Inventory) and studies that adapted existing scales for use during the pandemic (Cao et al., 2020; Islam et al., 2020; Son et al., 2020). However, we could not choose to include all items because, first, getting participants is difficult in Kenya and second we wanted to form our participants based on our framework that stresses collaborating with people on the ground. In this way, the online questionnaire was designed by the researchers and partners together based on their experiences. Items explored experiences of mental health and coping responses on a five-point Likert scale. Sample items included experiences of sadness, anxiety, and frustration, and response options ranged from $1=$ Never to $5=$ Always. Each was preceded by a common stem: "How frequently have you experienced the following since curfew/social distancing measures began?" Sample items involving coping responses include talking to family and friends, engaging in physical exercise, reading, and hobbies among others. Items were preceded by a common stem: "How frequently have you engaged in the following since the curfew/social distancing measures began?" and scored on a 5-point scale of $1=$ Never to $5=$ Always. Furthermore, a single item required respondents' evaluation of their overall mental health and responses ranged from $1=$ Poor to $5=$ Excellent. Responses were provided by selecting the appropriate item from a range of bulleted choices. To ensure accuracy of responses due to the nature of some items under study, a "not sure" option was provided rather than respondents being forced to fully commit themselves to fixed directional options. Questionnaire administration and recording of responses was self-running. 


\section{Data analysis}

As a result of factor analysis (FA) and exploratory graph analysis (EGA), psychosomatic problems (overall Cronbach's alpha $=0.83$ ) consists of five items representing psychological problems (sadness, anxiety, frustration, stress, loneliness) and three items representing somatization (change in sleep pattern, disruptive dreams, and bodily pains). Eigenvalues greater than one rule, scree and parallel plots for FA along with EGA results suggested this pattern of two factors (will be provided upon request). We further established a measurement model and checked the model fit. A two-factor structure along with covariance between two factors provided a good model fit $\left(\chi^{2}(19)=41.529\right.$, $p<0.01, \mathrm{CFI}=0.996$, TLI $=0.994$, RMSEA $=0.048)$. The correlation between the two factor is $0.471(p<0.001)$ which suggests a higher order factor structure (referred to as psychosomatic problems). In such cases, there are examples in the educational leadership literature in which scholars use composite sums via combining item raw scores for the subscales (e.g., Li et al., 2016; Thomas et al., 2020; Urick et al., 2019; Voelkel, 2019).

Considering a high overall $\alpha$, moderator and meaningful correlation between the two factors, and high model fit, we decided to merge the two factors for analysis and referred to this higher order factor as psychosomatic problems. We also conducted a sensitivity analysis to check whether separate analyses produced different coefficients for psychological problems subscale, somatic problems subscale, and the combined psychosomatic problems scale. Sensitivity analysis indicated that coefficients did not substantially differ from each other or the combined scale. We reported the model for the combined scale (higher order psychosomatic problems) model in the " 11 " section.

For the combined scale, first we ran two models to inspect additive effect of coping strategies (a model with demographic variables alone, and a model with demographic variables + coping strategies), and another two models to inspect whether age and gender moderated the relationship between coping strategies and psychosomatic problems. We used lme4 package (Bates et al., 2015) in the R environment (R Core Team, 2020) for this purpose.

\section{Procedures}

In this research, our theoretical framework constantly shaped the flow of the research. As explained above, EST and Community-Based Participatory Research (CBPR) affected the first researcher to attend to college students, some of whom he has served through different ways (e.g., providing mental health services during the pandemic and experiencing firsthand how it has been difficult for them). Following many calls and demands for mental health services, the researcher started to put a list of questions together for the research for more effective service. Then the researcher obtained an IRB for the study. Following that, the researchers asked some of these students if they want to be part of the process as partners and they all together shaped the final list of the questions in the study.

\section{Ethical considerations}

Potential participants were given an opportunity to ask questions and provide other feedback via an email address which was enjoined in the link before responding to the 
questionnaire. Informed consent information was attached to the first page of the online questionnaire detailing the voluntariness of the study, purpose, duration, procedure, risks, and benefits. They were asked to read and confirm their willingness to participate by clicking on "I agree." If a person clicked "I do not agree," a blank form was automatically submitted. No identifying information was to be provided in the responses. At the end of data gathering, respondents were thanked in their groups via a message posted to all the groups. Finally, groups were informed that a summary of the findings would be made available to them in their groups at the end of the study.

\section{Results}

After excluding respondents whose questionnaires were incomplete, data from 515 university students $(64.5 \%$ female, $n=334 ; 35.5 \%$ male, $n=184)$ were analyzed. Two thirds of students were 18-25 years old; $19.8 \%$ were $26-35$ years old, $9.3 \%$ were $36-45$ years old, while $3.9 \%$ were in the $46-55$ category.

The most commonly experienced mental health aspect was change in sleep patterns. More frequent experiences of sadness, anxiety, and frustration were also reported by more than $45 \%$ of respondents. In addition, up to a third of respondents reported having either "poor" or "fair" mental health during the isolation period. Talking to family and friends was the most frequently used coping approach.

Coping strategies had small to moderate correlations with psychosomatic problems, ranging from $r=-0.27(p<0.001)$ to $r=0.30(p<0.001)$. Highest correlation (negative) was observed between hobbies and age $(r=-0.46, p<0.001)$, meaning those older were less likely to pursue activities involving hobbies. Interestingly, the smallest correlation $(r=0)$ was observed between reading books and age (Table 1).

As expected, psychosomatic problems correlate positively with some variables and negatively with others suggesting convergent and discriminant validity (Table 2). Furthermore, high level of $\alpha$ and high model fit indicate high internal validity. These results also provide evidence indicating the convergent validity of the psychosomatic problems measure.

Table 1 Descriptive statistics for variables of interest

\begin{tabular}{lcccccc}
\hline Variable & Mean & SD & Min & Max & Skew & Kurtosis \\
\hline Psychosomatic problems & 21.23 & 6.59 & 10 & 38 & 0.23 & -0.80 \\
Age & 1.50 & 0.82 & 1 & 4 & 1.57 & 1.53 \\
Gender & 0.65 & 0.48 & 0 & 1 & -0.62 & -1.62 \\
Talking to family/friends & 4.18 & 0.88 & 2 & 5 & -1.25 & 1.12 \\
Exercise & 2.77 & 1.42 & 1 & 5 & 0.15 & -1.47 \\
Social media & 4.17 & 0.96 & 1 & 5 & -1.33 & 1.13 \\
Reading books & 3.04 & 1.31 & 1 & 5 & -0.15 & -1.37 \\
Hobbies & 3.85 & 1.08 & 1 & 5 & -0.79 & -0.55 \\
Spiritual activities & 3.54 & 1.39 & 1 & 5 & -0.56 & -1.10 \\
Alcohol/drugs & 1.37 & 0.95 & 1 & 5 & 2.83 & 7.06 \\
Seeking COVID-19 information & 3.51 & 1.21 & 1 & 5 & -0.6 & -0.82 \\
\hline
\end{tabular}

$N=515$. Gender: $0=$ male and $1=$ female. Age: $1=18-25$ years, $2=26-35$ years, $3=36-45$ years, $4=46-55$ years, and $5=56$ years and above. 


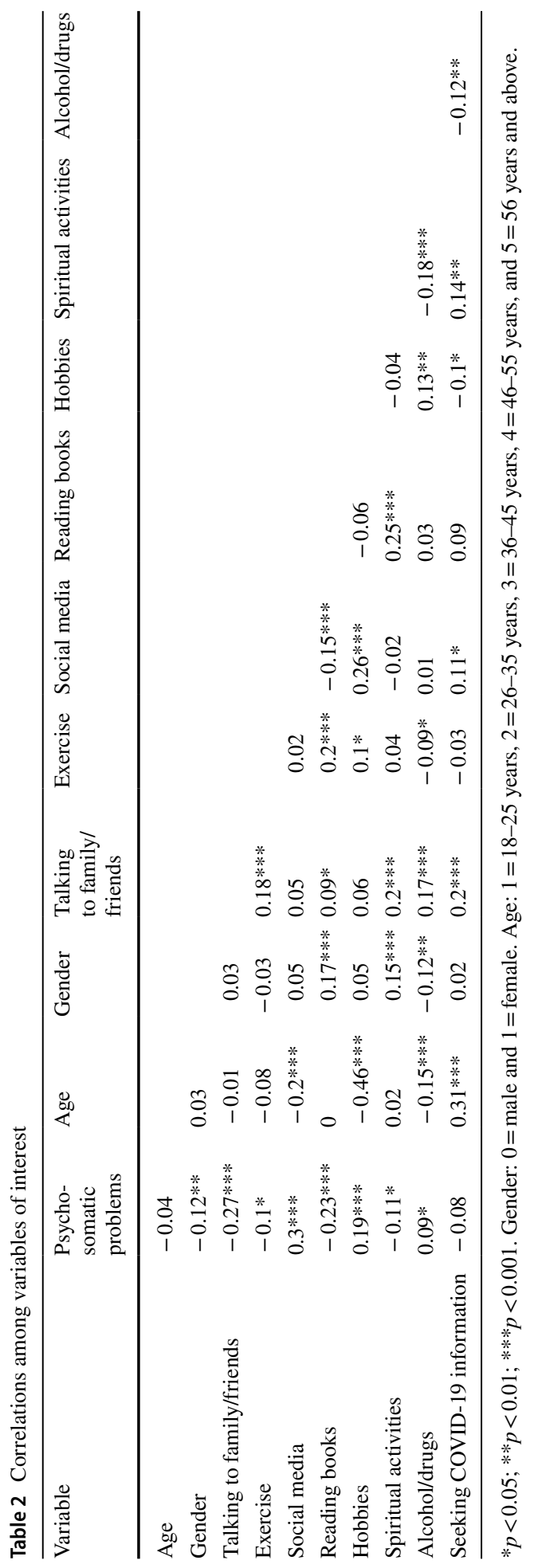


First we ran a regression model with demographic variables alone (Model 1) and another model with demographic variables + coping strategies (Model 2) using lme4 package (Bates et al., 2015) in the R environment (R Core Team, 2020). Model 1 in Table 3 indicates that gender and age explained a trivial amount of variance (1\%) in psychosomatic problems. Females experience psychosomatic problems less than males $(\beta=-0.12$, $p<0.001$ ), and this does not change substantially when coping strategies were added. However, the effect of age was amplified when coping strategies were added.

With the inclusion of coping strategies in model 2 , the model explained $24 \%$ of the variance in psychosomatic problems. Some coping strategies played a protective role while others were associated with aggravated psychosomatic problems. Talking to family and friends and reading books were associated with reduced psychosomatic problems $(\beta=-0.30, p<0.001$ and $\beta=-0.14, p<0.001$, respectively), whereas social media $(\beta=0.29, p<0.001)$, engaging in activities involving hobbies $(\beta=0.18, p<0.001)$, and alcohol/drugs $(\beta=0.13, p<0.001)$ were associated with aggravated psychosomatic problems. Results for exercise, spiritual activities, and seeking COVID-19 were inconclusive. Moreover, magnitude of standardized coefficients was trivial (Table 4).

We ran another two models to inspect whether gender and age moderated the relationship between coping strategies and psychosomatic problems. Model 3 indicates that gender moderated the effect of exercise $(\beta=-0.24, p<0.05)$, reading books $(\beta=-0.26, p<0.05)$ and engaging in activities involving hobbies $(\beta=0.46, p<0.01)$. This means exercise and reading potentially served as a protective factor for females more than it did for males, whereas engaging in activities involving hobbies was associated with more aggravated psychosomatic problems for females. In model 4, age moderated the effect of alcohol/drugs, meaning that being older was associated with aggravated psychosomatic problems.

\section{Discussion}

The survey aimed at investigating the experiences of university students living under government-sanctioned containment measures due to the COVID-19 pandemic and their coping strategies. This is a pioneering study in Kenya; therefore, we could not find other studies in Kenya to compare our results with. However, we compared the current results with other findings in other countries (Olaseni et al., 2020; Tanhan, 2020; Tanhan et al., 2020). Based on the third model, coping strategies and demographics together explained an important variance of psychosomatic problems, while most of the variance explained coming from the coping strategies. In addition, the total effect size of coping strategies on the psychosomatic problems indicates a moderate effect size. Therefore, from a research perspective, it is more worthy to focus on these coping strategies since in mental health they can be tailored more easily and effectively compared to demographic factors.

Based on these results, talking to family/friends seems to be the most important coping strategy. It appears that bonds with family and friends form a central support structure for college students in times of stress. In their research, Tanhan, 2020) found $26 \%$ of the college students reported not being able to physically spend time with their family, relatives, and friends and therefore feeling alone. The students expressed having social relationships as one of the most important barriers in terms of their biopsychosocial and spiritual health during the pandemic. On the other hand, $18 \%$ of the participants reported having social support (e.g., family, friends, relationship with others) to be one of the most important facilitators in terms of their psychosocial and spiritual wellbeing during the pandemic 


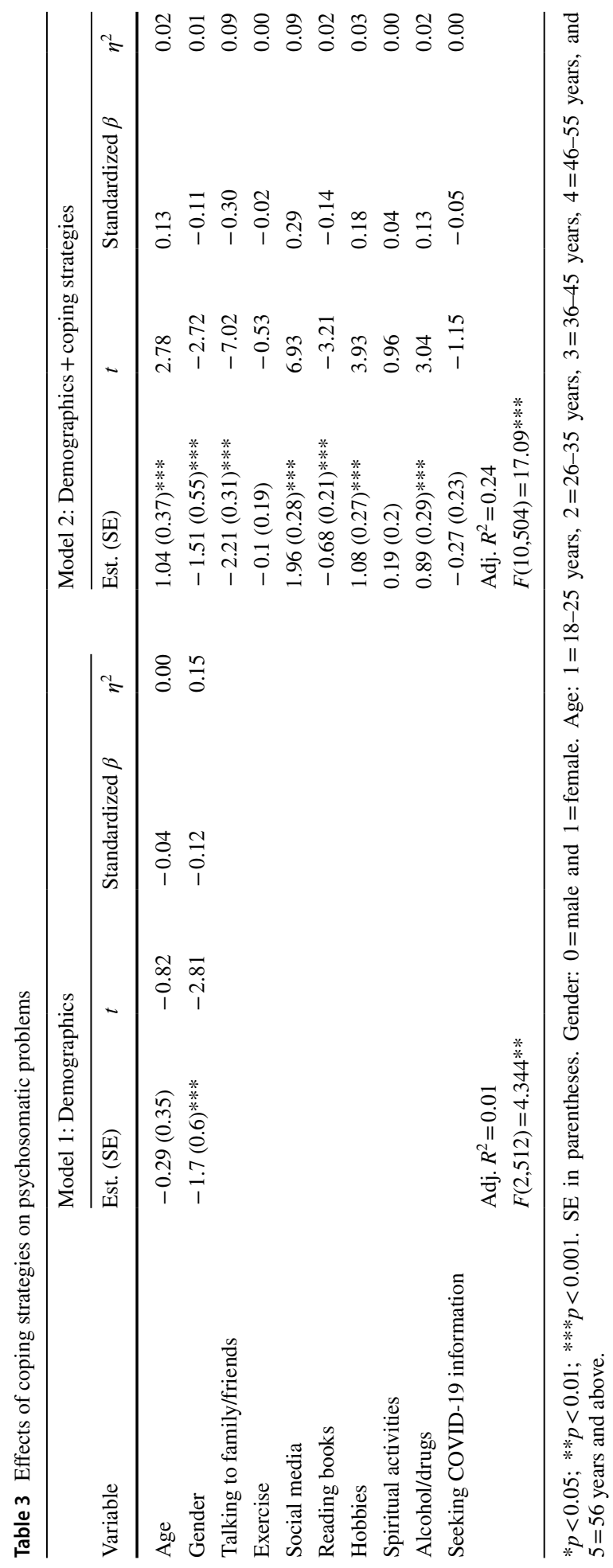




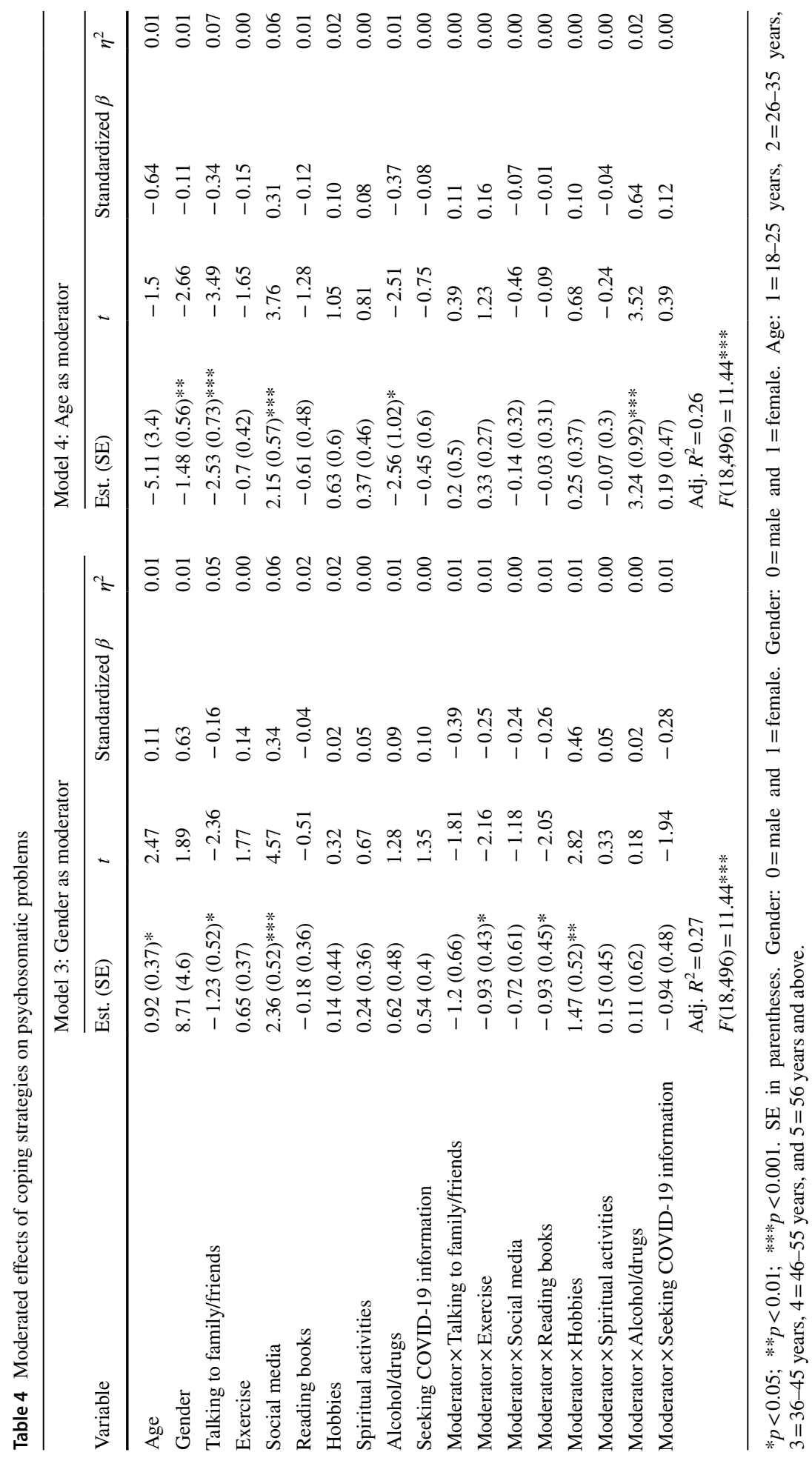


(Tanhan, 2020). In a similar Online Photovoice (OPV) study examining online/distance education during the pandemic, $16 \%$ of the participants reported lack of interaction or communication to be the most important concern and $20 \%$ of the participants reported being able to communicate with others as the most important support for their online education process (Doyumğaç et al., 2021). A recent study by August and Dapkewicz (2020) indicated that students who reported the self- and social-related benefit of coping strategies experienced less psychological distress experiences such as anxiety and stress during the coronavirus pandemic.

The second most effective coping strategy based on the regression model was social media. Consistent with these outcomes, Diefenbach (2017) has emphasized the positive aspects of human-technology interaction and discussed that technology use may be a potential resource for positive behavior change and oriented approaches such as solutionfocused coaching. This complies with some other research in which participants reported using technology for social connection and their mental health (10\%, Tanhan, 2020) and online education (Doyumğaç et al., 2021). Furthermore, hobbies had a small effect in the current study, and similarly, in Tanhan, 2020) study, the participants also reported different hobbies including spending time in nature $(17 \%, n=21)$, enjoying art $(13 \%, \mathrm{n}=17)$, and gaining some new hobbies like cooking (11\%) as some of the most important support for their home confinement process. In the current study, reading books also had a small effect. Similarly, Tanhan, 2020) found $12 \%$ of the participants to report "reading regular books" and $4 \%$ to report reading professionally selected books through an Online Read-ReflectShare (ORRS) bibliotherapy as an important resource for their biopsychosocial spiritual and economic wellbeing during the pandemic. Tanhan et al., (2020) also found their participants' satisfaction with each of the eight ORRS sessions ranged from 90 to $97 \%$, and 95\% of the participants recommended providing face-to-face or ORRS to others during COVID-19. The last coping skill, use of alcohol/drugs, also has a small effect. Some other researchers cautioned about use of substance and especially technology-related maladaptive coping skills and especially their long-term dysfunctional effect and called for wellgrounded empirical research and interventions (Tanhan, 2020; Tanhan et al., 2020).

Physical exercise, spiritual activities, and seeking COVID-19 formal information did not have a significant effect size by themselves on psychosomatic problems by themselves. Unlike our result, Tanhan, 2020) found physical exercise to be one of the most used coping strategy for some of the participants (3\%) and while an important part of the participants reported other activities (e.g., spending time in nature, 17\%; helping other with need, 9\%; gaining and keeping some new skills like physical exercise, drawing, and cooking, $11 \%$ ) that require somewhat physical exercise as the most important skills to protect and/ or enhance their wellbeing. In terms of spirituality, in Tanhan, 2020) study, 18\% of the college students reported practicing spiritual activities to be one of the most important facilitators for their biopsychosocial spiritual and economic state during the pandemic. Also in the same study, $5 \%$ of the participants reported formal local and national institutions like ministry of health providing professional information on the pandemic as helpful and protecting their mental health. A great lack of empirical and theoretical research, and especially research on this topic in Kenya limits our discussion. In the following paragraph, we briefly discussed other preliminary findings.

The current study found that the most commonly experienced mental health aspect was change in sleep patterns. Tanhan, 2020) in their qualitative research utilized Online Photovoice (OPV) methodology during the pandemic and found having a regular sleep pattern to facilitate college students' difficult home confinement process. A significant amount of the college students as the participants (4\%) reported having a regular sleep pattern and other 
daily life plan to be one of the most important facilitators for their mental health during the home confinement. In the same study, similarly, an important part (5\%) of the participants reported not being able to have a regular sleep pattern created one of the most important barriers for their mental health during the pandemic. The researchers stressed the role of having an effective and regular sleep pattern both in normal times and especially during such difficult times as the COVID-19. This implies that in times of crises, there is a likelihood of a high prevalence in sleep disturbances, with implications for mental health.

Moreover, study findings of frequent experiences of sadness, anxiety, and frustration support Zhai and Du (2020), Arslan et al. (2020), and Alsaqri et al. (2020) who argue that students tend to harbor emotional distress including frustration and anxiety. Tanhan, 2020) found similar results that college students experiencing psychological issues $(21 \%$; e.g., stress, anxiety, boredom, fear) and even more serious psychopathology (5\%; e.g., major depressive, anxiety, obsessive compulsive, online addiction, and bipolar disorders). Reports of loneliness can be attributed to loss of peer interactions and social relations. This is likely to pose a risk to their sense of belonging and may result in emotional distress if not well addressed. Recent literature (Fiorillo \& Gorwood, 2020) confirms that the COVID-19 pandemic is likely to leave a mental health impact comparable to that caused by traumatic events and disasters such as hurricanes, earthquakes, and floods among others. The difference is that whereas the former are relatively short-lived and affect specific areas, and can be escaped, the COVID-19 is invisible, spreads fast, and effects are global. With no end in sight to the pandemic, there is likelihood of increased fear, anxiety, and depression due to accompanying uncertainty with universities still closed.

Talking to family and friends and reading books were associated with reduced psychosomatic problems while social media, engaging in hobbies, and alcohol/drugs increased psychosomatic problems. These findings partially support studies that have found a wide range of similar coping strategies such as staying connected with family and friends, using online activities, and hobbies (Doyumğaç et al., 2021; Genç et al., 2021; Pariat et al., 2014; Subasi et al., 2021; Tanhan, 2020; Tanhan et al., 2021a, 2021b, 2021c; Tümkaya et al., 2021). With regard to gender differences, exercise and reading books served as protective factors for female students while engaging in hobbies was associated with aggravated psychosomatic problems among females. Age moderated the effect of using alcohol and drugs on psychosomatic problems, indicating that older students have higher likelihood of psychosomatic problems. These findings contradict Monteiro et al. (2014) who concluded that there was a likelihood of older students applying problem-solving strategies as opposed to younger counterparts. Age also predicted social media use with younger students tending to use social media forums more to deal with their stress. These results concur with Pastor et al. (2020) who reported more frequent use of internet and social media by students to counter distress and boredom.

\section{Conclusion and Recommendations}

Despite the spread of COVID-19 and its effects globally, there are concerns that many governments in Sub-Saharan Africa have paid scant attention to the negative psychological issues associated with the pandemic (Olaseni et al., 2020). There is a need for appropriate measures to be put in place to mitigate such effects and to ensure that proper support is offered to the students who continue to be in isolation. To lessen the psychological burden, the initial step could be to provide credible health-related information (Ministry of Health 
2020). The potential impact of the COVID-19 pandemic on the mental health of students underscores the need for preparedness and creating more awareness on how to deal with large-scale disasters and pandemics. It is important to formulate appropriate policies targeting higher learning institutions to better support students in times of crises such as the current pandemic. For instance, the use of psychological counseling services as a component of psychosocial support for students (Wang et al., 2020) and the provision of clear and appropriate mental health guidelines or manuals is imperative. As the pandemic ebbs and flows, more research is needed from across geographical regions and cultures to enable understanding of how students' mental health is affected and their coping strategies.

Although the study was based on a convenient sample of students with access to internet who may not represent the entire population of university students, findings highlight students' mental health experiences and their coping strategies during isolation. The findings may be important in formulating appropriate intervention programs to alleviate the mental issues that are likely to occur due to disasters or crises such as the current pandemic. Further, to our knowledge, this is the first study in sub-Saharan Africa to assess students' mental health outcomes in the context of COVID-19 isolation.

\section{Implications}

\section{Implications for Clinical Practice}

Many of the mental health issues among college students as a result of the pandemic have implications. It is worth noting that the long-term consequences of the pandemic are not fully known. These will need to be adequately addressed using a biopsychological-spiritual approach, which is multidimensional. Timely assessments to monitor the mental health status of the students and holistic intervention procedures may be beneficial. This calls for a combined effort from psychologists, psychiatrists, and other health practitioners to apply preventive as well as treatment strategies. Preventive interventions need to be put in place to cushion the students from the adverse effects of the pandemic. The findings of the study may create more awareness among college students regarding their mental health issues and the effects that pandemics are likely to have on them such as increased levels of stress and anxiety. Thus, educators in higher institutions of learning and mental health practitioners can capitalize on psychoeducation and building on students' coping skills. Furthermore, students could be assisted to draw from their individual strengths, past experiences, and personal resources. College administrations and other stakeholders may need to develop strong student support systems that will identify and address the needs of students and also enhance their social networks.

\section{Implications for Research}

We have a few implications for future researchers. First, the researchers can use our new measurement tools with different samples in Kenya to see their psychometric futures. Second, the researchers can conduct qualitative or mixed-method studies using Online Photovoice (OPV) to explore biopsychosocial spiritual and economic issues and strengths the college students experience from their own unique perspective. Tanhan and Strack (2020) developed OPV pre-COVID-19 and used it to examine US college students' biopsychosocial spiritual and economic concerns and strengths. Tanhan, 2020 used it during the 
pandemic for the same purpose considering the pandemic context. OPV is a qualitative phenomenological community-based participatory research method. Many researchers used OPV in the context of the pandemic to address different topics including close relationships (Genç et al., 2021), sexuality (Ozkan, 2021), online or distance education (Doyumğaç et al., 2021; Subasi et al., 2021; Tanhan et al., 2021b, 2021c; Tümkaya et al., 2021), mental health (Tanhan, 2020; Tanhan et al., 2021a), and special education (Öğülmüş et al., 2021). These researchers found OPV to be therapeutic, participant voice protecting and conveying, meaningful, collaborative, empirically and psychologically well grounded, and comprehensive. It is worth to use such innovative, effective, and comprehensive research methods in qualitative or mixed-method studies rather than just quantitative studies. Use of such innovative studies' results can be compared to quantitative results to get a more valid picture of what is happening with the college students. Additionally, more studies focusing on meaning among college students are needed (Tanhan, 2019, 2020; Y1ldırım et al., 2021).

\section{Limitations of the Study}

Some limitations of this study should be recognized and stated. The study being crosssectional in nature cannot be used effectively to determine cause and effect. The use of snowballing sampling method and the limited sample size may make our study findings not representative for the whole university student population. The study used self-report questionnaires that may raise issues regarding subjectivity and bias. Therefore, there may be need for further research with larger sample sizes and longitudinal designs. Although the structural validity and reliability analysis were conducted to examine psychometrics of the measure of the study, the measure might be considered as another limitation of this study. Future research is warranted to provide additional validity evidence (e.g., face, content) to increase usability of the measure in diverse samples.

Funding The authors had no external funding for this research. The authors financed all the charges for the current research.

Data Availability The datasets generated during and/or analyzed during the current study are available from the corresponding and the second authors on reasonable request.

\section{Declarations}

Conflict of Interes The authors declare no competing interests.

\section{References}

Alsaqri, S. H., Alkwiese, M. J., Aldalaykeh, M. K., Hamzi, M. I., Mahdi, M. M., \& Shafie, Z. M.(2020). Anxiety among the general population during Coronavirus-19 disease in Saudi Arabia: implications for a mental support program. medRxiv preprint. https://doi.org/10.1101/2020.05.07.20090225

August, R., \& Dapkewicz, A. (2020). Benefit finding in the COVID-19 pandemic: college students' positive coping strategies. Journal of Positive School Psychology. https://journalppw.com/index.php/JPPW/ article/view/245

Arslan, G., \& Tanhan, A. (2019). Ergenlerde okul aidiyeti, okul işlevleri ve psikolojik uyum arasındaki ilişkinin incelenmesi [Examining the association between school belonging, school functioning, and 
psychological adjustment in adolescents]. Journal of Education for Life, 33(2), 318-332. https://doi. org/10.33308/26674874.2019332127

Arslan, G., Yıldırım, M., Tanhan, A., Buluş, M., \& Allen, K. A. (2020). Coronavirus stress, optimismpessimism, psychological inflexibility, and psychological health: Psychometric properties of the coronavirus stress measure. International Journal of Mental Health and Addiction. https://doi.org/10.1007/ s11469-020-00337-6

Bates, D., Mächler, M., Bolker, B., \& Walker, S. (2015). Fitting linear mixed-effects models using lme4. Journal of Statistical Software, 67(1), 1-48. https://doi.org/10.18637/jss.v067.i01

Brooks, S. K., Webster, R. K., Smith, L. E., Woodland, L., Wessely, S., Greenberg, N., \& Rubin, G. J. (2020). The psychological impact of quarantine and how to reduce it: Rapid review of the evidence. Lancet, 395, 912-920. https://doi.org/10.1016/S0140-6736(20)30460-8

Calborean, V., Gheorman, V., Namat, R. A. L., Cazacu, I. M., Varju, P., Gede, N., Streba, C. T., Vere, C. C., Gheonea, D., \& Lungulescu, C. V. (2017). The association between stress level and laboratory parameters, sex, age and stage disease in patients with digestive and bronchopulmonary neoplasms. Revista de Chimie (Bucharest), 68(12), 3010-3014. https://doi.org/10.37358/RC.17.12.6028

Cao, W., Fang, Z., Hou, G., Han, M., Xu, X., Dong, J., \& Zheng, J. (2020). The psychological impact of the COVID-19 epidemic on college students in China. Psychiatry Research, 287, 112934. https://doi.org/ 10.1016/j.psychres.2020.112934

Ceri, V., \& Cicek, I. (2020). Psychological well-being, depression and stress during covid-19 pandemic in turkey: A comparative study of health care professionals and non-healthcare professionals. Psychology, Health \& Medicine. https://doi.org/10.1080/13548506.2020.1859566

Champely, S. (2020). pwr: Basic functions for power analysis. R package version 1.3-0. https://CRAN.Rproject.org/package $=$ pwr

Cohen, J. (1988). Statistical power analysis for the behavioral sciences (2nd ed.). Lawrence Erlbaum Associates.

Çiçek, I., Tanhan, A., Arslan, G., \& Bulus, M. (2021). Psychological inflexibility predicts depression and anxiety during COVID-19. Manuscript under review.

Çiçek, İ, Tanhan, A., \& Tanriverdi, S. (2020). COVID-19 ve Eğitim. Milli Eğitim Dergisi, 49(1), 10911104. https://doi.org/10.37669/milliegitim.787736

Diefenbach, S. (2017). Positive technology — a powerful partnership between positive psychology and interactive technology. A discussion of potential and challenges. Journal of Positive School Psychology, 2(1), 1-22.

Doyumğaç, İ, Tanhan, A., \& Kıymaz, M. S. (2021). Understanding the most important facilitators and barriers for online education during COVID-19 through online photovoice methodology. International Journal of Higher Education, 10(1), 166-190. https://doi.org/10.5430/ijhe.v10n1p166

Fiorillo, A., \& Gorwood, P. (2020). The consequences of the COVID-19 pandemic on mental health and implications for clinical practice. European Psychiatry, 63(1), e32 1-2. https://doi.org/10.1192/j. eurpsy.2020.35

Galea, S., Merchant, R., \& Lurie, N. (2020). The mental health consequences of COVID-19 and physical distancing: the need for prevention and early intervention. JAMA Internal Medicine. https://jaman etwork.com

Genç, E., Tanhan, A., \& Kose, O. (2021). Exploring the facilitators and barriers to intimate relationships during covid-19 through online photovoice methodology. Manuscript Under Review.

Goyal, K., Chauhan, P., Chhikara, K., Gupta, P., \& Singh, M. P. (2020). Fear of COVID-19: First suicidal case in India! Asian Journal of Psychiatry, 49, 101989. https://doi.org/10.1016/j.ajp.2020.101989

Hintz, S., Frazier, P. A., \& Meredith, L. (2015). Evaluating an online stress management intervention for college students. Journal of Counseling Psychology, 62(2), 137-147. https://doi.org/10.1037/cou00 00014

Holmes, E. A., O’Connor, R. C., Perry, V. H., Tracey, I., Wessely, S., Arseneault, L., Ballard, C., Christensen, H., Silver, R. C., Everall, I., Ford, T., John, A., Kabir, T., King, K., Madan, I., Mitchie, S., Przybylski, A. K., Shafran, R., Sweeney, A., Worthman, C. M., et al. (2020). Multidisciplinary research priorities for the COVID-19 pandemic: A call for action on mental health science. The Lancet Psychiatry, 7(6), 547-560. https://doi.org/10.1016/S2215-0366(20)30168-1

Islam, M. A., Barna, S. D., Raihan, H., Khan, M. N. A., \& Hossain, M. T. (2020). Depression and anxiety among university students during the COVID-19 pandemic in Bangladesh: A web-based cross-sectional survey. PLOS ONE, 15(8), e0238162. https://doi.org/10.1371/journal.pone.0238162

Khan, A. H., Sultana, S., Hossain, S., Hasan, M. T., Helal, U. A., \& Sikder, T. (2020). The impact of COVID-19 pandemic on mental health \& wellbeing among home-quarantined Bangladeshi students: A cross-sectional pilot study. Journal of Affective Disorders. https://doi.org/10.1016/j.jad.2020.07.135 
Kuo, B. C. (2011). Culture's consequences on coping: Theories, evidences, and dimensionalities. Journal of Cross-Cultural Psychology, 42(6), 1084-1100. https://doi.org/10.1177/0022022110381126

Kwok, K. O., Li, K. K., Wei, W. I., Tang, A., Wong, S. Y. S., \& Lee, S. S. (2021). Influenza vaccine uptake, COVID-19 vaccination intention and vaccine hesitancy among nurses: A survey. International Journal of Nursing Studies, 114, 103854. https://doi.org/10.1016/j.ijnurstu.2020.103854

Lazarus, R. S., \& Folkman, S. (1984). Stress, appraisal, and coping. Springer.

Li, L., Hallinger, P., \& Walker, A. (2016). Exploring the mediating effects of trust on principal leadership and teacher professional learning in Hong Kong primary schools. Educational Management Administration \& Leadership, 44(1), 20-42. https://doi.org/10.1177/2F1741143214558577

Liang, L., Ren, H., Cao, R., Hu, Y., Qin, Z., Li, C., \& Mei, S. (2020). The effect of COVID-19 on youth mental health. Psychiatric Quarterly. https://doi.org/10.1007/s11126-020-09744-3

Makhbul, Z. M., \& Hasun, F. M. (2011). Gender responses to stress outcomes. Journal of Global Management, 1(1), 47-55.

McLeod, S. (2015). Stress management. Simply Psychology. https://www.simplypsychology.org/stressmanagement.html

Mayordomo-Rodríguez, T., Meléndez-Moral, J. C., Viguer-Segui, P., \& Sales-Galán, A. (2015). Coping strategies as predictors of well-being in youth adults. Social Indicators Research, 122(2), 479-489. https://doi.org/10.1007/s11205-014-0689-4

Ministry of Health (April 1, 2020). A comprehensive guide on mental health and psychosocial support during the Covid-19 pandemic. www.health.go.ke>wp-content $>$ uploads $>2020 / 04$

Monteiro, N. M., Balogun, S. K., \& Oratile, K. N. (2014). Managing stress: The influence of gender, age and emotion regulation on coping among university students in Botswana. International Journal of Adolescence and Youth, 19(2), 153-173. https://doi.org/10.1080/02673843.2014.908784

Olaseni, A. O., Agberotimi, S. F., Oguntayo, R., \& Akinsola, O. S. (2020). Psychological distress experiences of Nigerians amid COVID-19 pandemic. Social Sciences \& Humanities Open. https://doi.org/10. 2139/ssrn.3596106

Ozkan, N., (2021). Farklı Ĕ̆itim Düzeyine Sahip Kadınların Cinselliğe Bakışının Online Seslifoto Yöntemi $(\mathrm{OSF})$ Ile Incelenmesi [Examining the views of women with different education levels about sexuality by using online photovoice methodology $(O P V)]$. Published master thesis, Üsküdar University, Institute of Social Sciences, Department of Clinical Psychology.

Öğülmüş, K., Acikgoz, M. H., \& Tanhan, A. (2021). Evaluation of teacher candidates' perceptions about specific learning difficulties through Online Photovoice (OPV) methodology. International Journal of Education and Literacy Studies, 9(2), 161-169. https://doi.org/10.7575/aiac.ijels.v.9n.2p.161

Panayiotou, G., Karekla, M., \& Leonidou, C. (2017). Coping through avoidance may explain gender disparities in anxiety. Journal of Contextual Behavioural Science, 6(2), 215-220. https://doi.org/10.1016/j. jcbs.2017.04.005

Pariat, L., Rynjah, A., Joplin, M., \& Kharjana, M. (2014). Stress levels of college students: Interrelationship between stressors and coping strategies. Journal of Humanities and Social Science, 19(8), 40-46.

Pfefferbaum, B., \& North, C. S. (2020). Mental health and the Covid-19 pandemic. New England Journal of Medicine. https://doi.org/10.1056/NEJMp2008017

R Core Team (2020). R: A language and environment for statistical computing. R Foundation for Statistical Computing, Vienna, Austria. https://www.R-project.org/

Selye, H. (1950). Stress and the general adaptation syndrome. British Medical Journal, 1(4667), 13831392. https://doi.org/10.1136/bmj.1.4667.1383

Shigemura, J., Ursano, R. J., Morganstein, J. C., Kurosawa, M., \& Benedek, D. M. (2020). Public responses to the novel 2019 coronavirus (2019-nCoV) in Japan: mental health consequences and target populations. Psychiatry and Clinical Neurosciences, 74(4), 281. https://doi.org/10.1111/pcn.12988

Shin, H., Park, Y. M., Ying, J. Y., Kim, B., Noh, H., \& Lee, S. M. (2014). Relationships between coping strategies and burnout symptoms: A meta-analytic approach. Professional Psychology: Research and Practice, 45(1), 44-56. https://doi.org/10.1037/a0035220

Son, C., Hegde, S., Smith, A., Wang, X., \& Sasangohar, F. (2020). Effects of COVID-19 on college students' mental health in the United States: Interview survey study. Journal of Medical Internet Research, 22(9), e21279. https://doi.org/10.2196/21279

Subasi, Y., Adalar, H., Tanhan, A., Arslan, G., \& Allen, K., Boyle, C., Lissack, K., \& Collett, K. (2021). College students' experiences of distance education in the context of COVID-19 through Online Photovoice (OPV). Manuscript under review.

Sundarasen, S., Chinna, K., Kamaludin, K., Nurunnabi, M., Baloch, G. M., Khoshaim, H. B., Hossain, S. F. A., \& Sukayt, A. (2020). Psychological impact of COVID-19 and lockdown among university students in Malaysia: implications and policy recommendations. International Journal of Environmental Research and Public Health, 17, 6206. https://doi.org/10.3390/ijerph17176206 
Tanhan, A. (2019). Acceptance and commitment therapy with ecological systems theory: addressing Muslim mental health issues and wellbeing. Journal of Positive Psychology and Wellbeing, 3(2), 197-219. https://doi.org/10.47602/jpsp.v3i2.172

Tanhan, A. (2020). COVID-19 sürecinde Online Seslifoto (OSF) yöntemiyle biyopsikososyal manevi ve ekonomik meseleleri ve genel iyi oluş düzeyini ele almak: OSF'nin Türkçeye uyarlanması. [Utilizing Online Photovoice (OPV) methodology to address biopsychosocial spiritual economic issues and wellbeing during COVID-19: Adapting OPV to Turkish.] Turkish Studies, 15(4), 1029-1086. https://doi. org/10.7827/TurkishStudies.44451

Tanhan, A., Arslan, G., Yavuz, K. F., Young, J. S., Çiçek, İ., Akkurt, M. N., Ulus, İ. Ç., Görünmek, E. T., Demir, R., Kürker, F., Çelik, C., Akça, M. Ş., Ünverdi, B., Ertürk, H., \& Allen, K. (2021a). A constructive understanding of mental health facilitators and barriers through Online Photovoice (OPV) during COVID-19. ESAM Ekonomik ve Sosyal Araştırmalar Dergisi, 2(2). Advance Online Publication. https://doi.org/10.13140/RG.2.2.15257.13921

Tanhan, A., Söğüt, Y., Cashwell, C. C., Taş, B., Genc, E., \& Karatepe, H. T. (2021b). Online education during COVID-19 through Online Photovoice (OPV) and community-based participatory research. Manuscript under review.

Tanhan, A., Taş, B., Agilkaya-Sahin, Z., Hayden, S. C. W., Korkmaz, O., \& Gürsu, O. (2021c). Perception of online education during covid-19: Online Photovoice (OPV) and ecological systems theory. Manuscript under review.

Tanhan, A., \& Francisco, V. T. (2019). Muslims and mental health concerns: A social ecological model perspective. Journal of Community Psychology, 47(4), 964-978. https://doi.org/10.1002/jcop.22166

Tanhan, A., \& Strack, R. W. (2020). Online photovoice to explore and advocate for Muslim biopsychosocial spiritual wellbeing and issues: Ecological systems theory and ally development. Current Psychology, 39, 2010-2025. https://doi.org/10.1007/s12144-020-00692-6

Tanhan, A., Yavuz K. F., Young, J. S., Nalbant, A., Arslan, G., Yıldırım, M., Ulusoy, S., Genç, E., Uğur, E., \& Çiçek, İ. (2020). A proposed framework based on literature review of online contextual mental health services to enhance wellbeing and address psychopathology during COVID-19. Electronic Journal of General Medicine, 17(6), em254. https://doi.org/10.29333/ejgm/8316.

Tanhan, A., \& Young, J. S. (2021a). Approaching mental health: social ecological model and theory of planned behavior/theory of reasoned action. International Journal of Eurasian Education and Culture, 6(14), 1967-2015. https://doi.org/10.35826/ijoecc.470

Tanhan, A., \& Young, J. S. (2021b). Muslims and mental health services: A concept map and a theoretical framework. Journal of Religion and Health. https://doi.org/10.1007/s10943-021-01324-4

Thomas, L., Tuytens, M., Devos, G., Kelchtermans, G., \& Vanderlinde, R. (2020). Transformational school leadership as a key factor for teachers' job attitudes during their first year in the profession. Educational Management Administration \& Leadership, 48(1), 106-132. https://doi.org/10.1177/17411 43218781064

Tümkaya, S., Kuşdemir Kayıran, B., Tanhan, A., \& Arslan, Ü. (2021). Using Online Photovoice (OPV) to understand youths' perceptions of distance education during COVID-19. Manuscript under review.

Urick, A., Liu, Y., Ford, T. G., \& Wilson, A. S. (2019). Does instructional leadership mediate effects of student home resources on opportunity to learn and math reasoning skills? A cross-national comparison of 4th grade students. International Journal of Leadership in Education, 1-39. https://doi.org/10.1080/ 13603124.2019 .1629697

Voelkel, R. H. (2019). Causal relationship among transformational leadership, professional learning communities, and teacher collective efficacy. International Journal of Leadership in Education, 1-22. https://doi.org/10.1080/13603124.2019.1690699

Wang, C., Cheng, Z., Yue, X. G., \& McAleer, M. (2020). Risk management of COVID-19 by universities in China. Journal of Risk and Financial Management, 13(2), 36. https://doi.org/10.3390/jrfm13020036

Yıldırım, M., Arslan, G., \& Özaslan, A. (2020). Perceived risk and mental health problems among healthcare professionals during covid-19 pandemic: Exploring the mediating effects of resilience and coronavirus fear. International Journal of Mental Health and Addiction. https://doi.org/10.1007/ s11469-020-00424-8

Yıldırım, M., Arslan, G., Green, Z. A., Ashraf, F., Sugawara, D., Tanhan, A., Asağlı, M., Helmy, M., \& Çiçek, İlhan. (2021). Validation and utility of the Meaning in Life Measure for Turkish university students. Journal of Happiness and Health, 1(1), 40-48. https://doi.org/10.47602/johah.v1i1.2

Zhai, Y., \& Du, X. (2020). Addressing collegiate mental health amid COVID-19 pandemic. Psychiatry Research, 288, 113003. https://doi.org/10.1016/j.psychres.2020.113003

Zimmer-Gembeck, M. J., \& Skinner, E. A. (2011). The development of coping across childhood and adolescence: an integrative review and critique of research. International Journal of Behavioural Development, 35(1), 1-17. https://doi.org/10.11177/0165025410384923 
Publisher's Note Springer Nature remains neutral with regard to jurisdictional claims in published maps and institutional affiliations.

\section{Authors and Affiliations}

\section{Habil Otanga ${ }^{1} \mathbb{D} \cdot$ Ahmet Tanhan ${ }^{2,3,4,5,6}$ (D) Phelista Marura Musılı ${ }^{7}$. Gökmen Arslan ${ }^{8,9}$ (D) Metin Buluş ${ }^{6}$}

1 Department of Psychology, University of Nairobi, Mombasa Campus, Kenya

2 Economic and Social Research Center-ESAM, Ankara, Turkey

3 Institute for Muslim Mental Health, Belleville, MI, USA

4 Association for Contextual Behavioral Sciences, Turkey Chapter, Istanbul, Turkey

5 Department of Counseling, The University of North Carolina at Greensboro, Greensboro, NC, USA

6 Department of Counseling, Adiyaman University, Adiyaman, Turkey

7 Department of Psychology, Kenyatta University, Nairobi, Kenya

8 Mehmet Akif Ersoy University, Burdur, Turkey

9 Centre for Wellbeing Science, University of Melbourne, Melbourne, Australia 